Check for updates

Cite this: Nanoscale Adv., 2019, 1 2840

Received 10th May 2019 Accepted 14th July 2019

DOI: $10.1039 / c 9 n a 00293 f$

rsc.li/nanoscale-advances

\section{Selective photothermal killing of cancer cells using LED-activated nucleus targeting fluorescent carbon dots $\dagger$}

\author{
Stephen A. Hill, (D) t $^{\mathrm{a}}$ Sadiyah Sheikh, (D) t $^{\mathrm{a}}$ Qiaoyu Zhang, ${ }^{\mathrm{a}}$ Lorena Sueiro Ballesteros, ${ }^{\mathrm{b}}$ \\ Andrew Herman, ${ }^{b}$ Sean A. Davis, ${ }^{a}$ David J. Morgan, D C Monica Berry, ${ }^{a}$ David Benito- \\ Alifonso ${ }^{a}$ and M. Carmen Galan (iD *a
}

\begin{abstract}
The development of effective theranostic probes in cancer therapy is hampered due to issues with selectivity and off-target toxicity. We report the selective LED-photothermal ablation of cervical (HeLa) cancer cells over human dermal fibroblasts (HDF) using a new class of green-emissive fluorescent carbon dots (FCDs). The FCDs can be easily prepared in one pot using cheap and commercial starting materials. Physico-chemical characterization revealed that a surface coating of 2,5-deoxyfructosazine on a robust amorphous core gives rise to the nanomaterial's unique properties. We show that intracellular uptake mostly involves passive mechanisms in combination with intracellular DNA interactions to target the nucleus and that cancer cell selective killing is likely due to an increase in intracellular temperature in combination with ATP depletion, which is not observed upon exposure to either the "naked" core FCDs or the surface components individually. The selectivity of these nanoprobes and the lack of apparent production of toxic metabolic byproducts make these new nanomaterials promising agents in cancer therapy.
\end{abstract}

Photothermal therapy (PTT) is a promising non-invasive therapeutic strategy, in which nanoparticles embedded within tumors generate heat, typically in response to exogenously applied light, for thermal ablation of cancer cells. ${ }^{1-3}$ PTT offers unique advantages in cancer therapy including high specificity, minimal invasiveness and precise spatial-temporal selectivity. ${ }^{4}$ A variety of photothermal nanotherapeutics (PTN) including noble metal nanostructures, nanocarbons, carbon dots, transition metal sulfide/oxide nanomaterials, and organic nano-

${ }^{a}$ School of Chemistry, University of Bristol, Cantock's Close, Bristol, UK. E-mail: M.C. Galan@bristol.ac.uk

${ }^{b}$ School of Cellular and Molecular Medicine, Faculty of Life Sciences Flow Cytometry Facility, University Walk, Bristol, UK

${ }^{c}$ Cardiff Catalysis Institute, School of Chemistry, Cardiff University, Park Place, Cardiff, $U K$

$\dagger$ Electronic supplementary information (ESI) available: Detailed experimental procedures and DLS, ZP, TGA, EA, FTIR, XPS, NMR, UV-vis and fluorescence spectroscopy results, and biological toxicity and assay characterization data. See DOI: $10.1039 /$ c9na00293f

\$ Equal contribution. agents have been extensively explored with encouraging results. ${ }^{2,5-9}$ However, one of the major challenges in PTT is the ability to selectively and efficiently find a biocompatible material that can target cancerous cells while avoiding non-specific heating of healthy cells upon irradiation and that does not generate toxic byproducts.,

Successful cancer therapy relies on early and accurate diagnosis, and fluorescence imaging has increasingly been recognized as a viable strategy to identify a range of cancers. ${ }^{\mathbf{1 1}, 12}$ Fluorescent probes that exhibit high stability, sensitivity and specificity for their target without the limitations of organic fluorophores and fluorescent proteins are of great interest in many areas of research, particularly in cellular biology, bioimaging and medical diagnostics. ${ }^{\mathbf{1 3 , 1 4}}$ Nanomaterials with novel optical, electronic and surface properties, have become useful platforms for a myriad of applications including imaging, drug delivery and diagnostics. ${ }^{15-17}$ Fluorescent carbon dots (FCDs) $)^{18-22}$ have emerged as a new class of non-isotopic detection labels suitable for live cell imaging, that provide a non-toxic alternative to heavy metal-containing fluorescent nanomaterials (e.g. quantum dots) while offering many advantages with regard to their ease and low cost of synthesis, unique photoluminescence (PL) properties, chemical inertness, high water solubility and generally low cytotoxicity. ${ }^{23-29}$

Previous work by our group ${ }^{28-34}$ and others ${ }^{35-38}$ on the use of water soluble fluorescent probes for live cell imaging applications has shown that the nanoparticle type, size, shape and surface functionalization have a significant effect on their intracellular uptake and localization. Encouraged by this, we embarked on the synthesis of a new class of fluorescent carbonbased nanomaterials (FCD-3) with unique surface functionality that could be used to target cancer cells and have potential applications in PTT.

Initial efforts were devoted to preparing a green-emitting nanomaterial that could be more easily imaged directly in live cells using confocal microscopy than the more common blueemitting FCDs. ${ }^{23,26,39-42}$ The synthesis of FCD-3 was thus achieved in one pot after three minutes of microwave heating 
(domestic $700 \mathrm{~W} \mathrm{MW}$ ) of glucosamine $\cdot \mathrm{HCl} 1$ and $m$-phenylenediamine 2 (Scheme 1A, see the ESI $\dagger$ for experimental details). ${ }^{43}$ Centrifugal filtration (10 kDa molecular weight cutoff) afforded monodisperse quasi-spherical FCD-3. The nanoparticles exhibited an average diameter of $2.42 \pm 0.55 \mathrm{~nm}$ (Fig. 1A) and an amorphous, carbonaceous core as determined by high-resolution transmission electron microscopy (HR-TEM, Fig. S2 $\dagger$ ). Dynamic light scattering (DLS) indicated a hydrodynamic diameter of 6-9 $\mathrm{nm}$ (Fig. S1A $\dagger$ ), while the zeta (electrokinetic) potential indicated a cationic surface of around $12 \mathrm{mV}$ (Fig. S1B $\dagger$ ). Thermogravimetric analysis (TGA) showed good core stability at high temperatures, while residual solvent and surface-adhered species were more loosely associated (95\% of the mass of FCD-3 was retained when heating to $150{ }^{\circ} \mathrm{C}$, while a $65 \%$ mass loss was recorded when reaching $650{ }^{\circ} \mathrm{C}$, see Fig. S3 $\dagger$ ). Fluorescence spectroscopy showed an excitationindependent emission for FCD-3 centered around $525 \mathrm{~nm}\left(\lambda_{\text {ex }}\right.$ $=350-500 \mathrm{~nm}$, Fig. 1B), indicative of emissive center uniformity. The quantum yield for FCD-3 was calculated to be $33 \%$ relative to fluorescein (Fig. S4 in the ESI $\dagger$ ) and shown to be photostable upon continuous $60 \mathrm{~min}$ irradiation with no significant decrease in emission intensity $\left(\lambda_{\mathrm{ex}}=460 \mathrm{~nm}, \lambda_{\mathrm{em}}=\right.$ $525 \mathrm{~nm}$, Fig. S5 and S6†). ${ }^{44}$ The photoluminescence (PL) properties remained unchanged in the presence of a different range of potential metal and organic quenchers $(500 \mu \mathrm{M})$, confirming the stability of FCD-3 (see Fig. S7 $\dagger$ ).

To ascertain the chemical composition of FCD-3, functional group analysis was conducted using Fourier-transformed infrared (FTIR) spectroscopy, X-ray photoelectron spectroscopy (XPS) and UV-vis spectroscopy. The FTIR signal at $3338 \mathrm{~cm}^{-1}$ was attributed to either residual carbohydrate architecture $(\mathrm{OH}$ groups) or $\mathrm{N}-\mathrm{H}$ bonds (Fig. S8†). Surface passivation was evidenced by the IR stretching at $1629 \mathrm{~cm}^{-1}(\mathrm{C}=\mathrm{O}$ amide) and minor peaks at $1016 \mathrm{~cm}^{-1}$ (C-O or $\mathrm{C}-\mathrm{N}$ functionality), while the broad signal at $612 \mathrm{~cm}^{-1}$ indicated $\mathrm{C}-\mathrm{Cl}$ bonds. The presence of mainly $\mathrm{C}, \mathrm{H}, \mathrm{N}, \mathrm{Cl}$ and $\mathrm{O}$ in FCD-3 was also confirmed by elemental and XPS analysis (Table S1 and Fig. S9†). Peak deconvolution of each element indicated the likely presence of a mixture of functionalities, e.g. for $\mathrm{O}$, aliphatic hydroxyl/ether $\mathrm{C}-\mathrm{O}$ or ester/imidate $\mathrm{O}^{*}-\mathrm{C}=\mathrm{O} / \mathrm{N}$; aromatic $\mathrm{OH}$ or $\mathrm{C}=\mathrm{O}$; for $\mathrm{N}$, amine/N-heteroaromatic motifs or $\mathrm{N}-\mathrm{C}=\mathrm{O}$ bridged

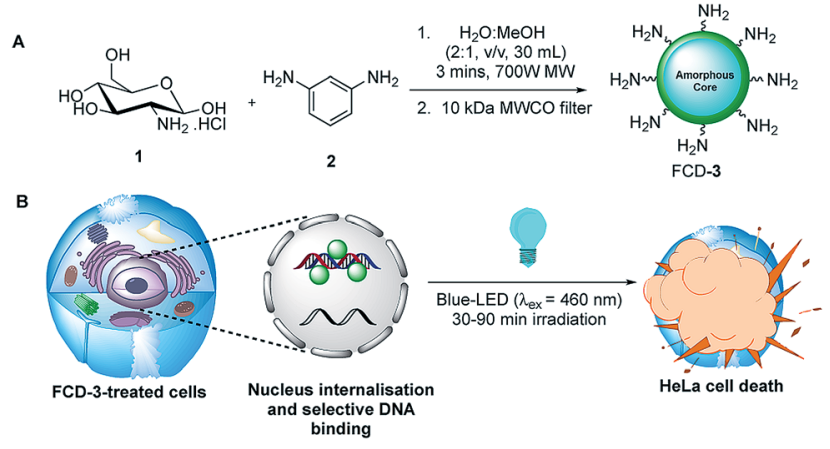

Scheme 1 (A) Three minute synthesis of green emitting FCD-3 and (B) FCD -3 nuclear targeting leading to photothermal cancer cell ablation after blue-LED irradiation.

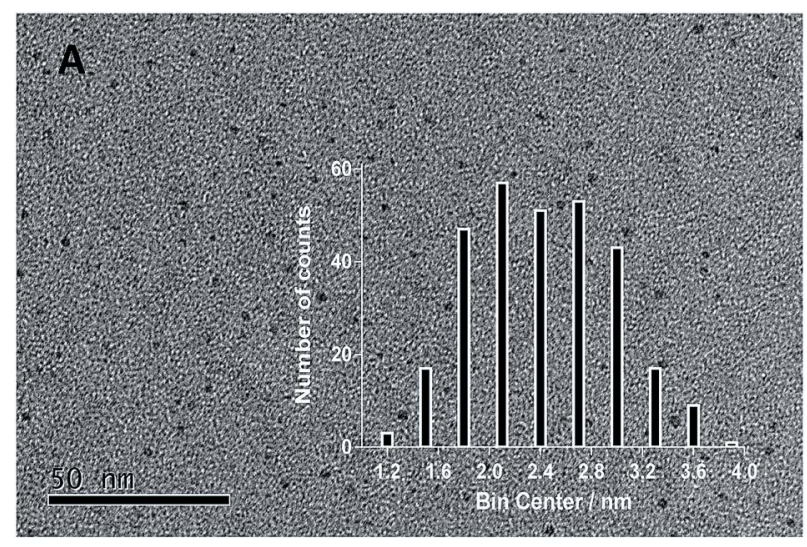

B

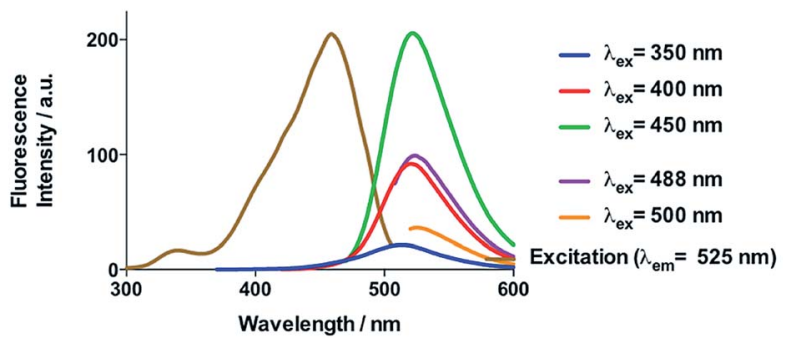

Fig. 1 (A) TEM image of FCD-3 and distribution of diameters between 1.8 and $3 \mathrm{~nm}$. (B) Fluorescence emission and excitation spectra showing that fluorescence emission is excitation independent.

structures; for $\mathrm{C}, \mathrm{C}-\mathrm{C}$ and $\mathrm{C}-\mathrm{OH} / \mathrm{C}-\mathrm{O}-\mathrm{C} / \mathrm{C}-\mathrm{N}$ bonds and minor peaks as $\mathrm{C}=\mathrm{O}$ and $\mathrm{O}-\mathrm{C}=\mathrm{O}$ species and for $\mathrm{Cl}, \mathrm{R}-\mathrm{NH}_{3} \cdot \mathrm{Cl}$ and C-Cl motifs (Fig. S10 and Table S2†). Additionally, UV-vis spectroscopy showed well-defined peaks at $212 \mathrm{~nm}, 260 \mathrm{~nm}$ (aromatic $\pi-\pi^{*}$ transitions), and $370 \mathrm{~nm}\left(\mathrm{n}-\pi^{*}\right.$ aromatic $\mathrm{C}=\mathrm{C}$ or $\mathrm{C}=\mathrm{O} / \mathrm{C}=\mathrm{N}$, Fig. $\mathrm{S} 11 \dagger)$, further confirming the presence of key functional groups. ${ }^{45,46}$

NMR analysis was used to shed further light on the molecular architectures found on FCD-3 (Fig. S12 $\dagger$ ). Pyrazine motifs were identified (three singlets at $\delta 8.51,8.30$ and $5.01 \mathrm{ppm}),{ }^{47}$ as probed by ${ }^{1} \mathrm{H},{ }^{1} \mathrm{H}-{ }^{13} \mathrm{C}$ HSQC and HMBC experiments, in addition to other complex N-hetero/aromatics akin to fructosazine and likely generated from 1,2-aminoaldose self-dimerisation ${ }^{48}$ (Fig. S13 and S14†). Polyhydroxylated species $(\delta 2.50-4.00 \mathrm{ppm})$, arising from incomplete glycan dehydration, ${ }^{\mathbf{4 9}}$ were also detected. Time-point ${ }^{1} \mathrm{H}$ and ${ }^{13} \mathrm{C}$ NMR analysis of reaction aliquots carried out at $30 \mathrm{~s}$ intervals up to $180 \mathrm{~s}$ (Fig. S15 and S16 in the ESI $\dagger$ ) showed loss of sugar anomeric signals from the starting carbohydrate in the spectra, indicative of pyranose ring-opening and iminium formation, followed by dehydration. ${ }^{29}$ Other aromatic structures were also detected in the spectra $(\delta 6.00-$ $7.50 \mathrm{ppm}$ ) suggesting the presence of complex polyaromatics. Indeed, ${ }^{1} \mathrm{H}-{ }^{13} \mathrm{C}$ HMBC analysis demonstrated the presence of $\mathrm{sp}^{2}$ and $\mathrm{sp}^{3}$-enriched surface domains.

Since nanoparticle surface composition is important for biological recognition, additional efforts were made to fully identify the surface molecular structures found on FCD-3. The material was thus subjected to Sephadex G15 size exclusion 
chromatography using methanol as the polar solvent to help separate non-covalently bound surface species from the coreFCD. In this manner, green fluorescent 2,5-deoxyfructosazine 4, which is a known product of glucosamine self-condensation, ${ }^{\mathbf{5 0 , 5 1}}$ was isolated as the major component in addition to core FCD-5 (FCD without 4) and FCD-3, as determined by ${ }^{1} \mathrm{H}$ NMR of the fractions (Fig. S17-S20 $\dagger$ and Scheme 2). ${ }^{52}$ Zeta potential measurements of core $5(-1.37)$ vs. 3 (12.05) showed a change from a slightly negative net charge to a cationic charge when 4 is conjugated to the naked core, as expected for a passivated surface. Moreover, diffusion ordered spectroscopy (DOSY) of FCD-3 showed that it had a single diffusion coefficient of $3.83 \times 10^{-6} \mathrm{~cm}^{2} \mathrm{~s}^{-1}$ confirming that 4 is associated with the FCD-core in FCD-3 (Fig. S20 $†$ ).

The utility of FCD-3 as a bioimaging tool was then investigated in HeLa cells (cervical cancer) and human dermal fibroblasts (HDF). It was found that FCD-3 $\left(50 \mu \mathrm{g} \mathrm{mL} \mathrm{m}^{-1}\right)$ was internalized in both cell lines, although the rate of uptake and intracellular localization differed between cell lines. Both active and passive cell transport mechanisms $\left(37{ }^{\circ} \mathrm{C} v s .4{ }^{\circ} \mathrm{C}\right)$ were observed, the latter accounting for $67 \%$ of fluorescence in HeLa, (Fig. S21†) but only 20\% in HDF (Fig. S24 and S25†). Interestingly, very rapid nuclear internalization of FCD-3 was observed for HeLa cells within 1 min (Fig. S22 $\dagger$ ), with maximum internalization at $5 \mathrm{~min}$ after which nuclear fluorescence decreased slightly due to increased cytosolic accumulation which plateaued after $24 \mathrm{~h}$ with an average Global Pearson Coefficient $(\mathrm{GPC})=0.62$ at $2 \mathrm{~h}$ exposure (Fig. 2 and 3 ). No significant colocalization of FCD-3 was observed for any other organelle (for representative images see Fig. S29-S36†). This result is significant as previous glucosamine-based blue-emitting FCDs $^{26,29,33}$ did not target the cell nucleus. In contrast, much slower overall cellular uptake of FCD-3 was detected for healthy HDF cells (Fig. S26 and S27 $\dagger$ ) with colocalization in the nucleus only seen after $2 \mathrm{~h}$ of continuous exposure $(\mathrm{GPC}=0.50$, Fig. S28†). Similarly, only nuclear and cytosolic accumulation was detected. These results might be linked to the different cell metabolic ratios associated with cancer $v s$. non-cancer cell lines. ${ }^{53}$

The nucleus contains most of the cell genetic material e.g. DNA, RNA, rRNA and proteins. ${ }^{54}$ Thus, it was proposed that

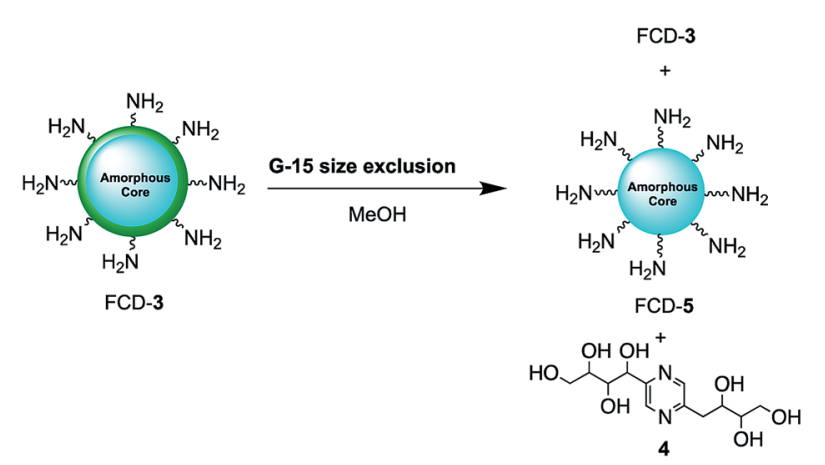

Scheme 2 2,5-Deoxyfructosazine 4 was isolated from FCD-3 after size exclusion chromatography.

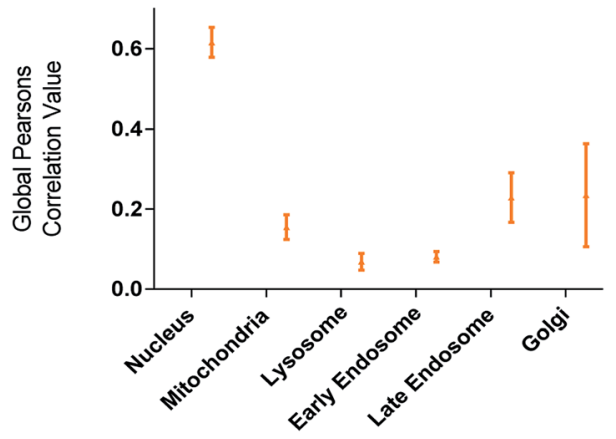

Fig. 2 Colocalisation values (average of global Pearson's correlation) for FCD-3 treated HeLa cells $\left(50 \mu \mathrm{g} \mathrm{mL}-1\right.$ after $2 \mathrm{~h}$ at $\left.37^{\circ} \mathrm{C}\right)$ with different organelle-selective fluorescent trackers.

favorable electrostatic interactions between FCD-3 and the phosphate backbone of polynucleotide chains might be responsible for the nuclear uptake observed. To evaluate this, cells were incubated with FCD-3 for $2 \mathrm{~h}$ at $37^{\circ} \mathrm{C}$ as before (see the ESI $\dagger$ for experimental details), before Förster resonance energy transfer (FRET) between FCD-3 (FRET donor) and cell permeable DNA (NuclearID-Red ${ }^{55}$ and DRAQ-5 (ref. 56)) or RNA (F22 RNASelect ${ }^{57}$ ) intercalating dyes as FRET acceptors was measured using flow cytometry (Fig. S37-S43†). For both cell lines, a FRET-associated decrease in emission was observed between FCD-3 and intercalating DNA-dyes. For instance, in HeLa cells FCD-3 donor emission decreased by $82 \%$ and $60 \%$ with Enzo NuclearID-Red and DRAQ-5 DNA dyes, respectively (Fig. S40 and S41†), and by $50 \%$ and $44 \%$ in HDF (Fig. S41 and $\mathrm{S} 42 \dagger){ }^{58}$ On the other hand, no RNA FRET-response was observed with F22 in HeLa and a minor reduction of $7 \%$ was seen in HDF (Fig. S40 and S43 $\dagger$ ), suggesting that DNA-mediated interaction with FCD-3 might be responsible for the observed internalization.

To evaluate the cytotoxicity of FCD-3, HeLa cells (cervical cancer) and human dermal fibroblasts (HDF) were continuously exposed to FCD-3 at concentrations from $10^{-3}$ to $2000 \mu \mathrm{g} \mathrm{mL}$ for $1 \mathrm{~h}, 1$ day, and 3 days (Fig. 4). Metabolic competence was assessed using Alamar Blue (AB), and the number of live cells was obtained with calcein. A concentration-dependent toxic effect was observed in both HeLa and HDF treated cells. For $\mathrm{HeLa}$, the lethal concentration $\left(\mathrm{LC}_{50}\right)$ was found to be $100 \mu \mathrm{g}$ $\mathrm{mL}^{-1}$ after three days of exposure, while higher concentrations of FCD-3 were tolerated at shorter exposure times $\left(\mathrm{LC}_{50}\right.$ at $1 \mathrm{~h}$ was $1500 \mu \mathrm{g} \mathrm{mL} \mathrm{mL}^{-1}$ ). Reductive metabolism (RM) was halved after $1 \mathrm{~h}$ of exposure to $500 \mu \mathrm{g} \mathrm{mL}{ }^{-1} \mathrm{FCD}-3$ and to $50 \mu \mathrm{g} \mathrm{mL}^{-1}$ after three days of exposure (Fig. S44 $\dagger$ ). In HDF cells (Fig. S45 $\dagger$ ), toxicity was detected at higher concentrations and/or longer exposure times to FCD-3 when compare to HeLa cells. $\mathrm{LC}_{50}$ was 10 times higher and $\mathrm{RM}_{50}$ was observed at $500 \mu \mathrm{g} \mathrm{mL}{ }^{-1}$ FCD-3 but only after three days of exposure. The observed differences in cytotoxicity for each cell line could be attributed to the different rates of cellular uptake and nuclear accumulation of FCD-3.

Next, we showed that photothermal activation of FCD-3 (500 $\mu \mathrm{g} \mathrm{mL} \mathrm{L}^{-1}$ ) in deionized $\mathrm{H}_{2} \mathrm{O}$ and cell media DMEM $(2 \mathrm{~mL})$ was 


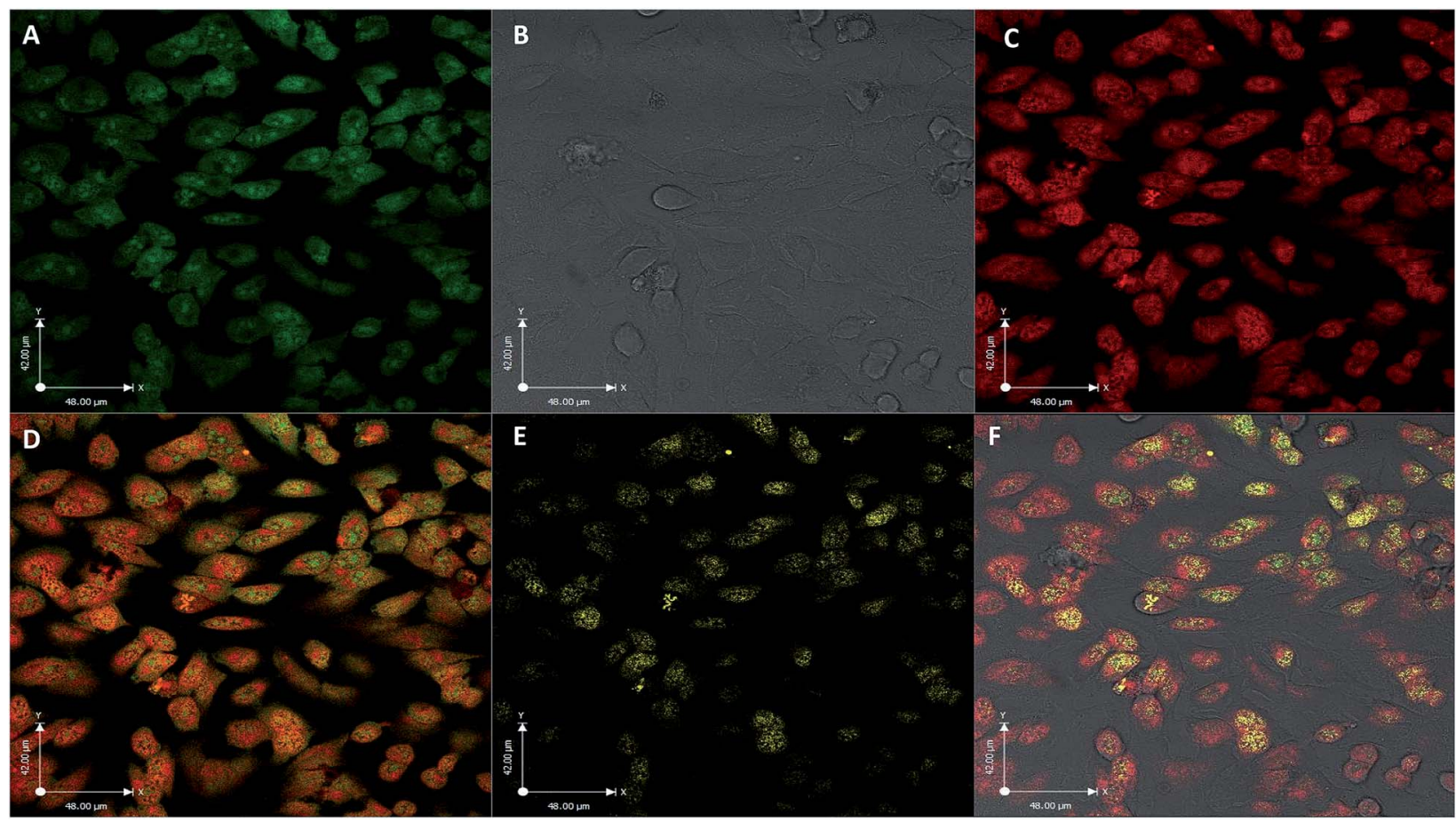

Fig. 3 Confocal fluorescence images of HeLa cells after exposure to FCD-3 (50 $\left.\mu \mathrm{g} \mathrm{mL}^{-1}, 2 \mathrm{~h}\right)$. (A) FCD-3 (green); (B) bright field; (C) nucleus tracker (NucRed647); (D) colocalization of FCD-3 and NucRed647 (yellow), (E) positive colocalization in yellow and (F) overlay of all channels.

possible using blue-light-emitting diodes (LEDs), which were chosen due to their low cost, ease of use, and widespread availability $\left(\lambda_{\mathrm{em}}=460 \mathrm{~nm}\right.$, Fig. S48†). Encouragingly, a $14{ }^{\circ} \mathrm{C}$ increase in temperature was measured after $90 \mathrm{~min}$ of illumination when compared to illumination of the solvent alone. Photothermal effects in FCD-3-treated cells post-illumination were then evaluated. An increase in temperature was also
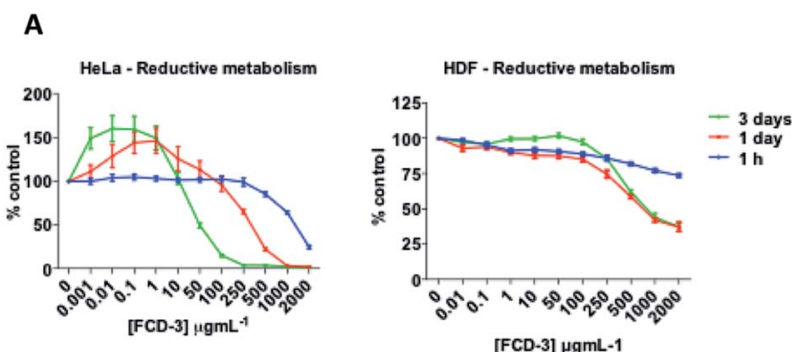

B
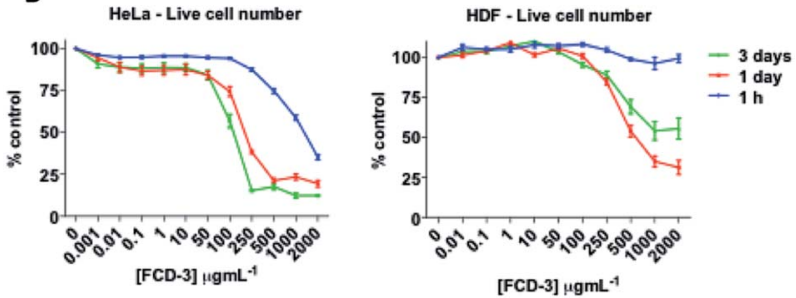

Fig. $4 \mathrm{HeLa}$ (left) and HDF (right) cells responses to incubation at $37^{\circ} \mathrm{C}$ with FCD-3 (0-2000 $\left.\mu \mathrm{g} \mathrm{mL}^{-1}\right)$ for $1 \mathrm{~h}, 1$ day or 3 days. (A) Reductive metabolism (RM); (B) viable cell numbers (calcein). Data referenced to untreated controls (100\%). recorded in the wells of HeLa exposed to FCD-3 for $2 \mathrm{~h}$ at room temperature during the $90 \mathrm{~min}$ blue-LED irradiation, when compared to controls (FCD-3-treated cells kept in the dark). The temperature increase was proportional to FCD-3 concentration (Fig. S49†). LED-irradiation of HeLa cells treated with $50 \mu \mathrm{g}$ $\mathrm{mL}^{-1}$ FCD-3 while keeping the cells at $37{ }^{\circ} \mathrm{C}$ resulted in temperatures reaching $56{ }^{\circ} \mathrm{C}$ after $90 \mathrm{~min}$, while the same experiment in HDF cells only recorded $44{ }^{\circ} \mathrm{C} .5^{59}$

Thermal increases in eukaryotic cells are known to have detrimental effects and lead to toxicity. ${ }^{60}$ To evaluate this, HeLa and HDF cells, cultured in 96-well plates, were exposed to FCD-3 at $1,10,50,100$ and $500 \mu \mathrm{g} \mathrm{mL} \mathrm{m}^{-1}$ for $2 \mathrm{~h}$, before irradiation with blue LEDs for 30, 60 or 90 min. The FCD-3 containing medium was then removed and fresh medium was added. Cellular health was then assessed after $1 \mathrm{~h}, 1$ day, and 3 days postillumination using $\mathrm{AB}$ and calcein as before and compared to controls (cells that have not been exposed to FCD-3 but were LED-irradiated for the same amount of time). Excitingly, significant cell death and decrease in metabolism were observed for HeLa cells after incubation with at least $10 \mu \mathrm{g}$ $\mathrm{mL}^{-1}$ FCD-3 followed by LED-irradiation (Fig. S50-S52†). In general, cell populations decreased by $75 \%$ and $80 \%$ after 1 day and 3 days post 30 min illumination when using concentrations as low as $50 \mu \mathrm{g} \mathrm{mL}{ }^{-1} \mathrm{FCD}-3$. Increasing the blue-LED irradiation time to 60 and 90 min increased the toxic effect in HeLa cells. Conversely, in $50 \mu \mathrm{g} \mathrm{mL}{ }^{-1} \mathrm{FCD}$-3-treated HDF cells after $30 \mathrm{~min}$ of illumination, RM was only diminished by $40 \%$ after 3 days (Fig. S53†) and only after exposures of up to $500 \mu \mathrm{g} \mathrm{mL} \mathrm{L}^{-1} \mathrm{FCD}-3$ a population reduction of $60 \%$ was observed after 1 day post30 min LED irradiation. Interestingly, at 3 days HDF cells were 
recovered with only a $20 \%$ reduction relative to controls. This apparent recovery was observed for HDF at all FCD-3 exposure concentrations and after all LED-irradiation times (Fig. S54 and $\mathrm{S} 55 \dagger$ ). These differences in cellular toxicity after LED illumination in both cell lines could be attributed to differences in photothermal activation which in turn are likely associated to the differential cellular uptake of the nanoprobes.

Since FCD-3 contains a robust FCD-core (5) coated with in situ generated 2,5-deoxyfructosazine $\mathbf{4}$, and with the knowledge that 4 is a versatile molecule with anti-diabetic and anti-inflammatory properties, ${ }^{\mathbf{5 0 , 6 1}}$ we wanted to determine whether FCD-3 or just 4 alone in solution was responsible for the cell killing effects observed. To this end, HeLa cells were incubated with FCD-3, 4 or core FCD-5 at two different concentrations (50 and $100 \mu \mathrm{g} \mathrm{mL}$ with regard to the concentration of 4 ) for $2 \mathrm{~h}$ at $37^{\circ} \mathrm{C} .{ }^{62}$ Following the same process as before, the cells were then subjected to LED irradiation or kept in the dark for $60 \mathrm{~min}$ after which cell viability and metabolism were measured after 24 and $72 \mathrm{~h}$ and compared to controls (Fig. 5, S56 and S57†). Generally, no significant toxicity was observed in cells incubated with either 4 or FCD-5 either in the dark or under LED illumination, and only cells incubated with FCD-3 and subjected to LED-illumination showed an 80-90\% reduction in cell viability as before. ${ }^{63}$

To better understand the mechanism of toxicity, dihydroethidium (DHE) was used next to assess the production of cytosolic reactive oxygen species (ROS) in FCD-3-treated cells $1 \mathrm{~h}$ post illumination. In both HeLa and HDF, ROS production levels were similar to those of dark controls, except with exposure to FCD-3 of $500 \mu \mathrm{g} \mathrm{mL} \mathrm{m}^{-1}$ and 90 min illumination which diminished DHE cytoplasm fluorescence by $50 \%$ in HeLa cells (Fig. 6). These results suggest that differences between HDF and HeLa responses to FCD-3 exposure/blue-LED illumination are not likely ROS associated.

Anaerobic glycolysis which produces adequate adenosine $5^{\prime}$ triphosphate (ATP) and biological components is the hall-mark
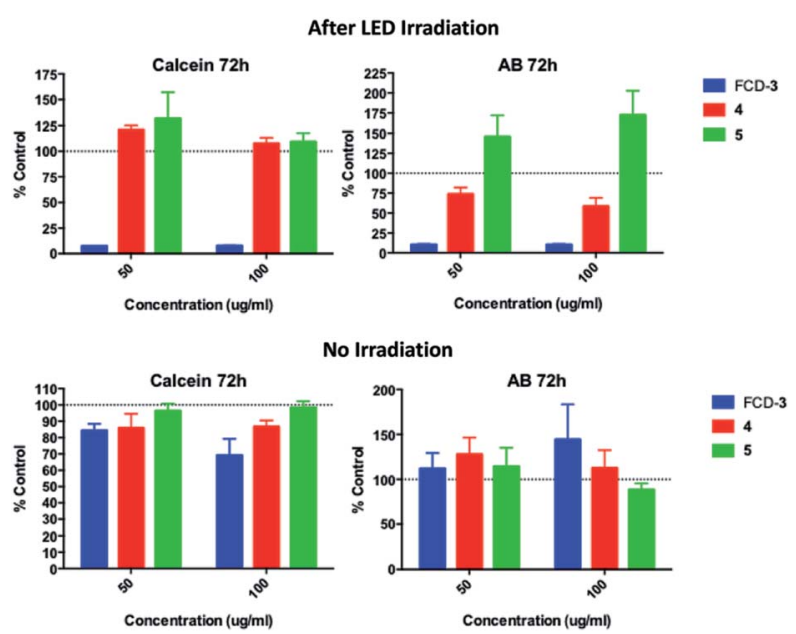

Fig. 5 HeLa cell viability (calcein) and metabolism (AB) for cells incubated with FCD-3, 4 or 5 and post 60 min LED irradiation or in the dark. Data referenced to untreated controls subjected to the same illumination conditions (shown as 100\%).

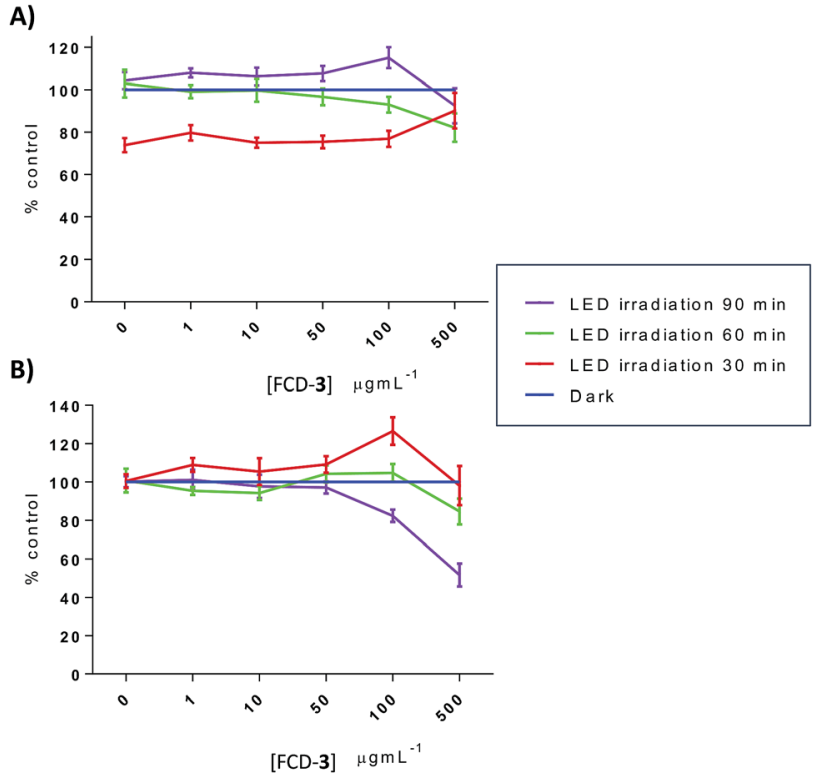

Fig. 6 Percentage of cytosolic DHE fluorescence loss induced by reactive oxygen species (ROS) after exposure to $F C D-3 /$ blue-LED treatment relative to non-irradiated (dark) controls exposed to equal concentrations of 3 in (A) HeLa cells and (B) HDF cells.

of cancers to meet the rapid metabolic requirements. ${ }^{64}$ To investigate whether ATP levels had been affected upon treatment with FCD-3 and LED irradiation, intracellular ATP levels were determined in HeLa cells using a luciferin-luciferase luminescence ATP detection assay. HeLa cells were exposed to FCD-3 at 1, 10, 50, 100 and $500 \mu \mathrm{g} \mathrm{mL}{ }^{-1}$ and incubated for $2 \mathrm{~h}$ before $90 \mathrm{~min}$ blue-LED irradiation. ATP determination was conducted at $1 \mathrm{~h}, 1$ day and 3 days post-illumination. Controls kept in the dark did not experience a significant reduction in ATP levels after exposure to FCD-3. However, in cultures irradiated with blue-LED, ATP levels were reduced in a concentration-dependent manner with 1 day and 3 day levels being diminished by $65 \%$ and $75 \%$, respectively, at $1 \mu \mathrm{g} \mathrm{mL} \mathrm{m}^{-1}$ FCD-3, relative to dark controls (Fig. 7).

To explore if metabolic products derived from FCD-3 exposure to cells could induce toxicity, naïve HeLa and HDF cells were incubated with the supernatant and lysates of FCD-3 exposed cultures at different concentrations (1-500 $\mu \mathrm{g} \mathrm{mL} \mathrm{mL}^{-1}$ ) for $2 \mathrm{~h}$ before 90 min blue-LED illumination. FCD-3 suspended in the cell culture medium in the absence of cells was irradiated as the control and RM and live cell numbers were quantified after 1 day of exposure. Cell lysates caused no toxic effects in either HeLa or HDF cells. Supernatants of irradiated HeLa cells were toxic only at the highest concentration of FCD-3 $\left(500 \mu \mathrm{g} \mathrm{mL}{ }^{-1}\right)$, as determined by measuring cell viability and reductive metabolism (Fig. S58 and S59†), while no significant effects were measured in HDF cells at all concentrations tested (Fig. S60 and S61†). Moreover, NMR spectroscopy analysis of pre- and post-90 min illumination of FCD-3 in water revealed no visible changes in the structure of the FCDs (Fig. S62 $\dagger$ ). These results suggest that the cytotoxicity observed is not likely due to the generation of new metabolic or photochemical FCD by-products. 


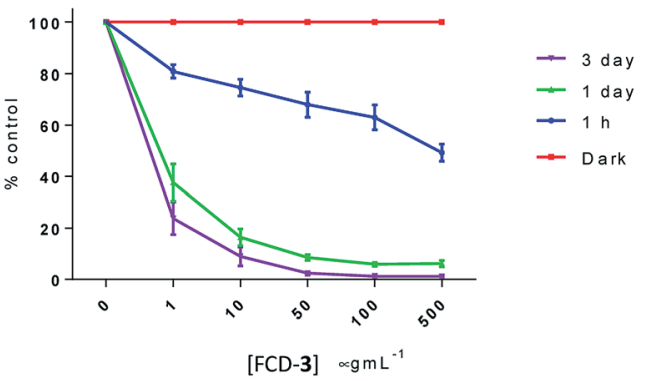

Fig. 7 ATP depletion in HeLa after $2 \mathrm{~h}$ of exposure to FCD-3 followed by 90 min blue-LED illumination compared to non-irradiated (dark) controls at equal FCD-3 exposures. ATP luminescence was measured after cells were washed and after a period of $1 \mathrm{~h}, 1$ day or 3 days under standard culture conditions.

\section{Conclusions}

In conclusion, we have developed a facile, three minute largescale synthesis of a novel green-emissive carbon-based nanomaterial FCD-3 that can be used to target HeLa cancer cells preferentially over healthy epithelial HDF cells under mild activation conditions. The carbon-based probe contains a stable amorphous core and is decorated with 2,5-deoxyfructosazine $\mathbf{4}$ as the major component, which together give rise to the nanomaterial's unique properties. We demonstrate that FCD-3 is internalized into both HeLa and HDF cells partly through passive mechanisms and trafficked into the nucleus by interactions with DNA, albeit at significantly distinct rates depending on the cell line. This differential uptake can be exploited in the LED-activated selective killing of HeLa over HDF cells after $60 \mathrm{~min}$ of LED-illumination using as little as $50 \mu \mathrm{g} \mathrm{mL} \mathrm{L}^{-1} \mathrm{FCD}-3$. The killing is believed to be caused by an increase of intracellular localized temperature followed by ATP depletion. Interestingly, neither the FCD core $\mathbf{5}$ or surface component $\mathbf{4}$ are individually able to induce cancer cell death as observed for FCD-3. Furthermore, we show that metabolic products from FCD-3 treated cells do not elicit toxic effects on naïve cells. These novel metal-free bifunctional nanoprobes have the potential, with further development, to be effective theranostic agents in cancer therapy.

\section{Conflicts of interest}

There are no conflicts to declare.

\section{Acknowledgements}

This research was supported by EPSRC CAF EP/L001926/1 and ERC-COG: 648239 (MCG), EPSRC EP/G036764/1 (SAH) and EPSRC EP/L016648/1 (SS). Thanks to Dr D. Alibhai (Wolfson Bioimaging Facility) for confocal assistance, and TEM imaging was performed at the Chemistry Imaging Facility with equipment funded by the UoB and EPSRC (EP/K035746/1 and EP/ M028216/1).

\section{Notes and references}

1 A. M. Alkilany, L. B. Thompson, S. P. Boulos, P. N. Sisco and C. J. Murphy, Adv. Drug Delivery Rev., 2012, 64, 190-199.

2 (a) V. Shanmugam, S. Selvakumar and C. S. Yeh, Chem. Soc. Rev., 2014, 43, 6254-6287; (b) Z. Zhang, J. Wang and C. Chen, Adv. Mater., 2013, 25, 3869-3880.

3 Z. J. Zhang, J. Wang and C. H. Chen, Adv. Mater., 2013, 25, 3869-3880.

4 L. L. Zou, H. Wang, B. He, L. J. Zeng, T. Tan, H. Q. Cao, X. Y. He, Z. W. Zhang, S. R. Guo and Y. P. Li, Theranostics, 2016, 6, 762-772.

5 M. Orecchioni, R. Cabizza, A. Bianco and L. G. Delogu, Theranostics, 2015, 5, 710-723.

6 X. G. Ding, C. H. Liow, M. X. Zhang, R. J. Huang, C. Y. Li, H. Shen, M. Y. Liu, Y. Zou, N. Gao, Z. J. Zhang, Y. G. Li, Q. B. Wang, S. Z. Li and J. Jiang, J. Am. Chem. Soc., 2014, 136, 15684-15693.

7 J. T. Robinson, S. M. Tabakman, Y. Y. Liang, H. L. Wang, H. S. Casalongue, D. Vinh and H. J. Dai, J. Am. Chem. Soc., 2011, 133(17), 6825-6831.

8 Y. Wang, K. Y. Wang, J. F. Zhao, X. G. Liu, J. Bu, X. Y. Yan and R. Q. Huang, J. Am. Chem. Soc., 2013, 135, 4799-4804.

9 B. J. Geng, D. W. Yang, D. Y. Pan, L. Wang, F. F. Zheng, W. W. Shen, C. Zhang and X. K. Li, Carbon, 2018, 134, 153162.

10 R. S. Riley and E. S. Day, WIREs Nanomedicine and Nanobiotechnology, 2017, 9, e1449.

11 R. Alford, M. Ogawa, P. L. Choyke and H. Kobayashi, Mol. BioSyst., 2009, 5, 1279-1291.

12 R. Jenkins, M. K. Burdette and S. H. Foulger, RSC Adv., 2016, 6, 65459-65474.

13 H. Zhu, J. L. Fan, J. J. Du and X. J. Peng, Acc. Chem. Res., 2016, 49, 2115-2126.

14 Y. H. Chan and P. J. Wu, Part. Part. Syst. Charact., 2015, 32, 11-28.

15 S. M. Janib, A. S. Moses and J. A. MacKay, Adv. Drug Delivery Rev., 2010, 62, 1052-1063.

16 J. Xie, S. Lee and X. Chen, Adv. Drug Delivery Rev., 2010, 62, 1064-1079.

17 M. A. Hahn, A. K. Singh, P. Sharma, S. C. Brown and B. M. Moudgil, Anal. Bioanal. Chem., 2011, 399, 3-27.

18 W. Liu, C. Li, Y. Ren, X. Sun, W. Pan, Y. Li, J. Wang and W. Wang, J. Mater. Chem. B, 2016, 4, 5772-5788.

19 H. Li, Z. Kang, Y. Liu and S.-T. Lee, J. Mater. Chem., 2012, 22, 24230-24253.

20 S. Y. Lim, W. Shen and Z. Gao, Chem. Soc. Rev., 2015, 44, 362381.

21 S. N. Baker and G. A. Baker, Angew. Chem., Int. Ed., 2010, 49, 6726-6744.

22 X. Xu, R. Ray, Y. Gu, H. J. Ploehn, L. Gearheart, K. Raker and W. A. Scrivens, J. Am. Chem. Soc., 2004, 126, 12736-12737.

23 S. Y. Lim, W. Shen and Z. Q. Gao, Chem. Soc. Rev., 2015, 44, 362-381.

24 P. Miao, K. Han, Y. G. Tang, B. D. Wang, T. Lin and W. B. Cheng, Nanoscale, 2015, 7, 1586-1595. 
25 S. N. Baker and G. A. Baker, Angew. Chem., Int. Ed., 2010, 49, 6726-6744.

26 S. Hill and M. C. Galan, Beilstein J. Org. Chem., 2017, 13, 675693.

27 N. L. Teradal and R. Jelinek, Adv. Healthcare Mater., 2017, 6, 1700574.

28 T. A. Swift, M. Duchi, S. A. Hill, D. Benito-Alifonso, R. L. Harniman, S. Sheikh, S. A. Davis, A. M. Seddon, H. M. Whitney, M. C. Galan and T. A. A. Oliver, Nanoscale, 2018, 10, 13908-13912.

29 S. A. Hill, D. Benito-Alifonso, D. J. Morgan, S. A. Davis, M. Berry and M. C. Galan, Nanoscale, 2016, 8, 18630-18634.

30 D. Benito-Alifonso, S. Tremel, B. Hou, H. Lockyear, J. Mantell, D. J. Fermin, P. Verkade, M. Berry and M. C. Galan, Angew. Chem., Int. Ed., 2014, 53, 810-814.

31 B. Hou, D. Benito-Alifonso, R. Webster, D. Cherns, M. C. Galan and D. J. Fermin, J. Mater. Chem. A, 2014, 2, 6879-6886.

32 B. T. Miles, A. B. Greenwood, D. Benito-Alifonso, H. Tanner, M. C. Galan, P. Verkade and H. Gersen, Sci. Rep., 2017, 7, 44666.

33 S. A. Hill, D. Benito-Alifonso, S. A. Davis, D. J. Morgan, M. Berry and M. C. Galan, Sci. Rep., 2018, 8, 12234.

34 D. Benito-Alifonso, B. Richichi, V. Baldoneschi, M. Berry, M. Fragai, G. Salerno, M. C. Galan and C. Nativi, ACS Omega, 2018, 3, 9822-9826.

35 R. Levy, U. Shaheen, Y. Cesbron and V. See, Nano Rev., 2010, 1, 4889.

36 M. Lundqvist, J. Stigler, G. Elia, I. Lynch, T. Cedervall and K. A. Dawson, Proc. Natl. Acad. Sci. U. S. A., 2008, 105, 14265-14270.

37 D. Bartczak, O. L. Muskens, S. Nitti, T. Sanchez-Elsner, T. M. Millar and A. G. Kanaras, Small, 2012, 8, 122-130.

38 H. Yuan, A. M. Fales and T. Vo-Dinh, J. Am. Chem. Soc., 2012, 134, 11358-11361.

39 J. Hou, W. Wang, T. Zhou, B. Wang, H. Li and L. Ding, Nanoscale, 2016, 8, 11185-11193.

40 R. Bandi, B. R. Gangapuram, R. Dadigala, R. Eslavath, S. S. Singh and V. Guttena, RSC Adv., 2016, 6, 28633-28639.

41 C. X. Yang, R. P. Thomsen, R. Ogaki, J. Kjems and B. M. Teo, J. Mater. Chem. B, 2015, 3, 4577-4584.

42 S. Y. Liu, N. Zhao, Z. Cheng and H. G. Liu, Nanoscale, 2015, 7, 6836-6842.

43 A series of aryl diamines were screened with 2 giving the optimum results.

$449 \%$ emission loss was measured on heating to $65{ }^{\circ} \mathrm{C}$ (Fig. S6†).

45 K. Jiang, S. Sun, L. Zhang, Y. Wang, C. Cai and H. Lin, ACS Appl. Mater. Interfaces, 2015, 7, 23231-23238.
46 K. Jiang, S. Sun, L. Zhang, Y. Lu, A. Wu, C. Cai and H. Lin, Angew. Chem., Int. Ed., 2015, 54, 5360-5363.

47 H. Sommer, H. J. Bertram, G. E. Krammer, C. O. Schmidt, W. Stumpe, P. Werkhoff and M. Zviely, Magn. Reson. Chem., 2000, 38, 907-917.

48 H. I. Hwang, T. G. Hartman, R. T. Rosen, J. Lech and C. T. Ho, J. Agric. Food Chem., 1994, 42(4), 1000-1004.

49 T. Shibamoto and R. A. Bernhard, Agric. Biol. Chem., 1977, 41(1), 143-153.

50 A. Zhu, J. B. Huang, A. Clark, R. Romero and H. R. Petty, Carbohydr. Res., 2007, 342(18), 2745-2749.

51 L. Y. Jia, Y. X. Wang, Y. Qiao, Y. Q. Qi and X. L. Hou, RSC Adv., 2014, 4(83), 44253-44260.

52 It is of note that while 4 is likely a product of glucosamine self condensation, this compound is not observed in the presence of different diamines (e.g. TTDA or $\beta$-alanine) as in our previous reports.

53 M. M. Keenan and J. T. Chi, Cancer J., 2015, 21(2), 49-55.

54 M. O. J. Olson, in eLS, John Wiley \& Sons, Ltd, 2001.

55 A. Hubert, J. M. Henderson, K. G. Ross, M. W. Cowles, J. Torres and R. M. Zayas, Epigenetics, 2013, 8(1), 79-91.

56 K. Wojcik and J. W. Dobrucki, Cytometry, Part A, 2008, 73(6), 555-562.

57 Q. Li, Y. Kim, J. Namm, A. Kulkarni, G. R. Rosania, Y.-H. Ahn and Y.-T. Chang, Chem. Biol., 2006, 13(6), 615-623.

58 The acceptor emission for NuclearID-Red and DRAQ-5 did not exhibit a global increase, in-line with FRET donor decrease (Fig. S40 and S41†). It was suspected that an excess amount of dye relative to FCD-3 would be present intracellularly. Therefore, only a small proportion of the dye molecules would be localized within FRET distance (1$10 \mathrm{~nm}$ ) of 3, masking the global acceptor emission increase.

59 The temperatures were obtained from media in each well where cells were present; nucleus temperatures were likely to be a bit higher.

60 W. Enrico, R. K. Tobias, S. Roland, W. F. Anatol, Z. Mareike and A. K. Josef, New J. Phys., 2014, 16(7), 073009.

61 A. Bhattacherjee, Y. Hrynets and M. Betti, J. Agric. Food Chem., 2017, 65(23), 4642-4650.

62 Cells incubated with 4 at $37^{\circ} \mathrm{C}$ showed nuclear intracellular uptake (data not shown) suggesting that 4 plays a key role in the nuclear transport in FCD-3.

63 An increase of around $14{ }^{\circ} \mathrm{C}$ in temperature was measured after 90 min of illumination for 3, 4 and 5 in DMEM cell media $\left(12.5{ }^{\circ} \mathrm{C}\right.$ in $\left.\mathrm{H}_{2} \mathrm{O}\right)$, when compared to illumination of the media alone (see Fig. S48 in the ESI $\dagger$ ). Since we show that temperature increase is proportional to [FCD-3] within the cell (Fig. S49†), differences in killing observed for the three components are likely linked to differences in uptake. 64 F. Roder, Philos. Sci., 1956, 23(4), 343-347. 